\title{
Worldwide Prevalence of Epidermal Growth Factor Receptor Mutations in Non-Small Cell Lung Cancer: A Meta-Analysis
}

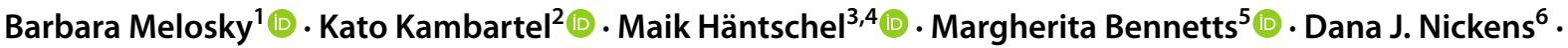 \\ Julia Brinkmann ${ }^{7} \cdot$ Antonin Kayser $^{7}$ (1) Michael Moran ${ }^{7,9}$ (i) $\cdot$ Federico Cappuzzo $^{8}$ (i)
}

Accepted: 17 October 2021 / Published online: 23 November 2021

(c) The Author(s) 2021

\begin{abstract}
Background Identification of variable epidermal growth factor receptor $(E G F R)$ gene mutations in non-small cell lung cancer (NSCLC) is important for the selection of appropriate targeted therapies. This meta-analysis was conducted to provide a worldwide overview of EGFR mutation and submutation (specifically exon 19 deletions, exon 21 L858R substitutions, and others) prevalence, and identify important covariates that influence $E G F R$ mutation status in patients with advanced NSCLC to address this clinical data gap.

Methods Embase ${ }^{\circledR}$ and MEDLINE ${ }^{\circledR}$ in Ovid were searched for studies published between 2004 and 2019 with cohorts of $\geq 50$ adults with EGFR mutations, focusing on stage III/IV NSCLC ( $\leq 20 \%$ of patients with stage I/II NSCLC). Linear mixed-effects models were fitted to EGFR mutation endpoints using logistic transformation (logit), assuming a binomial distribution. The model included terms for an intercept reflecting European studies and further additive terms for other continents. EGFR submutations examined were exon 19 deletions, exon 21 L858R substitutions, and others.

Results Of 3969 abstracts screened, 57 studies were included in the overall EGFR mutation analysis and 74 were included in the submutation analysis relative to the overall EGFR mutation population (Europe, $n=12$; Asia, $n=51$; North America, $n=5$; Central America, $n=1$; South America, $n=1$; Oceania, $n=1$; Global, $n=3$ ). The final overall EGFR mutations model estimated Asian and European prevalence of $49.1 \%$ and $12.8 \%$, respectively, and included an additive covariate for the proportion of male patients in a study. There were no significant covariates in the submutation analyses. Most submutations were actionable: exon 19 deletions (49.2\% [Asia]; 48.4\% [Europe]); exon 21 L858R substitutions (41.1\% [Asia];
\end{abstract} $29.9 \%$ [Europe]).

Conclusions Although EGFR mutation prevalence was higher in Asian than Western countries, data support worldwide testing for $E G F R$ overall and submutations to inform appropriate targeted treatment decisions.

Barbara Melosky

BMelosky@bccancer.bc.ca

1 Medical Oncology, British Columbia Cancer Agency, The University of British Columbia, 600 West 10th Avenue, Vancouver Centre, Vancouver, BC V5Z 4E6, Canada

2 Krankenhaus Bethanien, Moers, Germany

3 University Hospital and Faculty of Medicine Tübingen, Tübingen, Germany

4 Division of Pulmonology, Cantonal Hospital Winterthur, Winterthur, Switzerland

5 Pfizer R\&D UK Ltd., Sandwich, UK

6 Pfizer Inc., La Jolla, CA, USA

7 Pfizer Pharma GmbH, Berlin, Germany

8 Istituto Nazionale Tumori "Regina Elena", Rome, Italy

9 Present Address: AbbVie Deutschland GmbH \& Co. KG, Wiesbaden, Germany

\section{Key Points}

Testing for EGFR mutations is important for the selection of appropriate therapy.

Herein, EGFR overall and actionable submutation prevalence was high, with regional differences.

These data support testing for EGFR gene mutations to inform treatment decisions.

\section{Introduction}

Lung cancer, of which the non-small cell type accounts for almost $85 \%$ of cases, is the most commonly diagnosed cancer and the leading cause of cancer-related deaths worldwide [1,2]. Overall, it was predicted that in 2018 (the year for which the latest statistics are available), there would be 
2.1 million new diagnoses of lung cancer and 1.8 million associated deaths [1]. Not all cases of non-small cell lung cancer (NSCLC) are created equal, and NSCLC can be further classified on the basis of histology as adenocarcinoma, which makes up about $40 \%$ of cases [3], squamous cell carcinoma, and large cell type, among other rare types [4]. Prognosis is primarily linked to the stage of disease, with the highest 5-year survival (61\%) in those diagnosed with localized disease, which accounts for only about $30 \%$ of adenocarcinoma cases at diagnosis, falling to only $6 \%$ in those with distant metastatic disease, which encompasses about $50 \%$ of cases [5, 6]. In addition, a variety of tumorspecific genomic abnormalities have been identified that provide insight into prognosis and predict response to specific targeted therapies, particularly for adenocarcinoma [7].

The epidermal growth factor receptor (EGFR) is a transmembrane protein that serves as a tyrosine kinase receptor for a variety of ligands involved in regulating cell proliferation, differentiation, and survival [8]. Mutations in EGFR were the first targetable alterations discovered in lung cancer and are among the most common driver mutations in NSCLC [9]. Before the introduction of targeted therapies, NSCLC with overexpression of EGFR was associated with a greater risk of metastasis, poor tumor differentiation, and a high rate of tumor growth $[8,10]$. The first drugs that targeted EGFR were approved without a complete understanding of the genomic mutations associated with EGFR positivity. These tyrosine kinase inhibitors (TKIs) function by competitively inhibiting the binding of adenosine triphosphate to the active site of the EGFR kinase. Since then, mutations have been identified that have been shown to be associated with sensitivity to EGFR TKIs, with the most common being in-frame deletions of exon 19 and L858R substitutions in exon 21 [11]. Tumor genotyping is now considered to be essential to guide treatment decisions for patients with NSCLC, and EGFR mutations are now listed among several mutations that should be routinely screened in patients with lung cancer with an adenocarcinoma component $[12,13]$. Newer non-invasive analytical options, such as the analysis of circulating tumor DNA, offer high specificity as well as the testing of patients for whom biopsy sampling is not feasible [13].

Patients with advanced (regional and distant) disease, which totals $70 \%$ of cases, have few therapeutic options [5]. Historically, the standard of care has been systemic therapy involving platinum-based regimens; however, an overall survival of less than 2 years is associated with this modality in patients with advanced NSCLC $[14,15]$. Clinical trial results have supported the advances in the genomics, showing significantly higher response rates and longer progression-free survival with EGFR TKIs compared with chemotherapy in patients whose tumors harbored activating mutations in $E G F R$, prompting the approval of these agents for first-line treatment of patients with $E G F R$-positive NSCLC and universal testing of tumors for EGFR mutations $[16,17]$. As confirmed in clinical studies, epidemiologic and retrospective database investigations have found that testing for genetic mutations and the use of appropriate targeted therapies have led to better therapeutic outcomes in advanced NSCLC $[18,19]$. Thus, the identification of geographically different $E G F R$ gene mutation patterns in NSCLC is important for the selection of appropriate targeted therapies. However, current studies give an incomplete picture of regional differences in EGFR mutation and submutation prevalence. This meta-analysis was conducted to provide a robust and comprehensive overview of EGFR mutation and submutation (specifically exon 19 deletions, exon 21 L858R substitutions, and others) prevalence, and identify important covariates that influence $E G F R$ mutation status in patients with advanced NSCLC worldwide to address this clinical data gap.

\section{Materials and Methods}

This systematic review and meta-analysis abided by the Preferred Reporting Items for Systematic Reviews and MetaAnalysis (PRISMA) statement guidelines [20]. A predefined protocol was followed.

\subsection{Criteria for Study Inclusion}

Studies included in this meta-analysis comprised phase II and III randomized controlled trials, real-world datasets, health record datasets, cohort studies, case-control studies, and cross-sectional studies. Case reports, preclinical studies, opinion pieces, letters, other systematic reviews, and phase I randomized controlled trials were excluded. Studies must have enrolled $\geq 50$ adult patients with advanced NSCLC (stage IIIB/IV; locally [T3-T4] and/or regionally [N2-N3] advanced or distant metastatic [M1] disease [12, 21]) who tested positive for an EGFR mutation; up to $20 \%$ of patients could be stage I/II was added as an allowance after an initial search. Studies that did not explicitly state the stage were included if there were other indications suggesting that patients with advanced/metastasized disease were almost exclusively enrolled.

Studies must have had EGFR mutational data available, with clear distinctions between exon 19 deletions, exon 21 L858R substitutions, and other submutations. Studies where mutational analyses were performed on tissue were included, but studies in which only test results from blood or malignant pleural effusion were provided were excluded, as were studies that did not include patients with adenocarcinoma or if the study specifically looked at the T790M resistance mutation in patients who had undergone TKI therapy. 


\subsection{Search Strategy}

Embase $^{\circledR}$ and MEDLINE ${ }^{\circledR}$ in Ovid were searched for studies published between 2004 and 2019. A title and abstract screen was performed independently by a pair of the authors (JB, $\mathrm{MM})$. An additional screen was performed by two reviewers (JB, AK), with disagreements resolved by consensus. Duplicates were removed, and then a full-text screen was performed by one of the authors (AK), with disagreements resolved by consensus (AK, JB, and MM).

\subsection{Data Synthesis}

Study-level EGFR mutation endpoints (All EGFR, exon 19 deletions, and exon 21 L858R substitutions) reported as percentages were converted into binomial probabilities prior to the meta-analysis. Missing study-level mutation counts were converted from percentages and vice versa. Where there was no study-level mutation information, baseline arm values were used to calculate study-level information. Covariate values were converted in a similar manner, with weighted averages employed for mean age. Where required, All EGFR mutation percentages were calculated using the number of patients evaluated for EGFR mutations as the denominator. Submutation percentages were calculated using the number of patients with any EGFR mutation as the denominator.

Associated EGFR mutation standard errors, used to weight each study, were derived using the log-odds approximation where " $p$ " was the probability of EGFR mutation and " $n$ " was either the number of tested subjects in the study (for the All EGFR analysis) or the number of patients with All $E G F R$ mutations (for the submutation analyses).

$\mathrm{SE} \approx \sqrt{\frac{1}{n p}+\frac{1}{n(1-p)}}$

Linear mixed-effects models were fitted to EGFR mutation endpoints using logistic transformation (logit) and assuming a binomial distribution (EGFR mutation $\sim$ binomial $\left[n_{i}, p_{i}\right]$, where $n_{i}$ is the number of tested subjects in the study or the number with All EGFR mutations depending on the endpoint and $p_{i}$ is the probability of the specific $E G F R$ mutation endpoint in the study). The model included terms for an intercept reflecting European studies, further additive terms $\mathrm{C}_{i}-\mathrm{C}_{i}$ for other study continents (categorical $=0$ or 1$)$, a between-trial random effect $\left(\eta_{i} \sim N\left[0, \tau^{2}\right]\right)$, and a residual random error term $\left(\varepsilon_{i} \sim N\left[0, \sigma^{2} / n_{i}\right]\right)$, where $i$ is the study and $\theta$ is the model estimate:

$$
\begin{aligned}
\operatorname{Logit}\left(p_{i j}\right)= & \text { intercept }+\theta_{1} * C 1_{i}+\theta_{2} * C 2_{i}+\theta_{3} * C 3_{i} \\
& +\theta_{4} * C 4_{i}+\theta_{5} * C 5_{i}+\theta_{6} * C 6_{i}+\eta_{i}+\varepsilon_{i}
\end{aligned}
$$

Five potential covariates (age, percent male, percent Caucasian, percent adenocarcinoma, and percent stage I/II) were assessed visually for their relationship to the response. Only covariates with values for at least $70 \%$ of the studies and the majority of those values covering more than one level were included. Missing covariates were imputed as median percentages. Three covariates (age, percent male, and percent adenocarcinoma) were tested as additive terms in the model, each added as a single term. The covariates were centered on the mean for the logistic regression model; therefore, model estimates were assessed at the mean value of the covariate. Analysis was conducted in R [22], with the lme4 package [23], and figures produced using the package ggplot2 [24].

\section{Results}

\subsection{Study Identification and Selection}

Upon the initial title and abstract screen, 3969 potential studies were identified, of which 2974 were eliminated because they were duplicates or it was clear that they did not meet the prespecified criteria upon visual review. Of the remaining 995 studies reviewed in more detail, 914 were excluded because they did not meet inclusion criteria. Data extraction of the remaining 81 studies eliminated an additional 11 studies, including two studies that did not differentiate between exon 19 deletions and exon 21 L858R substitutions, four that did not examine any rare mutations, one that enrolled $<50$ patients with an EGFR mutation, one that had only malignant pleural effusion specimens, and three that included $>20 \%$ of patients with stage I/II disease. Five additional studies were added: one that was not listed in the primary literature search and found by chance, and four that were initially incorrectly excluded. This left 75 studies, of which one had submutation population overlap that did not allow for individual percentages of patients with each submutation to be calculated and was therefore excluded. Of the final 74 studies that were included, 17 comprised populations that were non-representative of the typical overall NSCLC population (e.g., because of specific selection criteria) and were removed from the All EGFR mutation analysis, leaving 57 studies. The selection process of studies is shown in Fig. 1.

\subsection{Characteristics of the Study Populations}

The 74 studies enrolled a total of 59,707 patients who were tested for $E G F R$ mutations, with 16,746 patients in the European studies, 37,594 patients from Asia, 3332 patients from North America, and 1298 patients from more than one global region, which encompassed multiple regions. There was a paucity of data from some continents. No South 
Fig. 1 Flow diagram of the selection of studies included in this meta-analysis. EGFR epidermal growth factor receptor

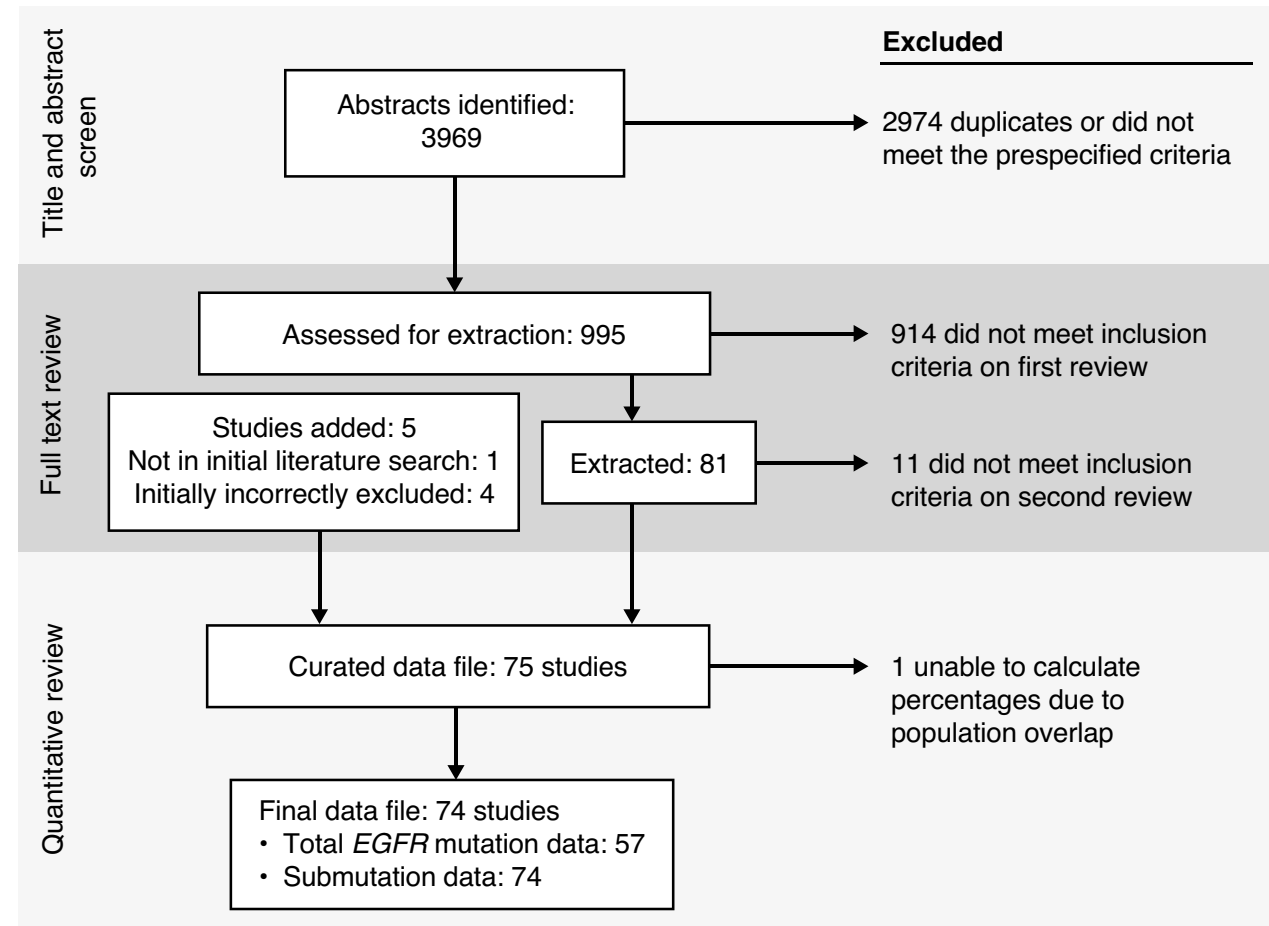

American studies were included in the All EGFR mutation analysis, and the one study included in the submutation analysis had only 72 patients. Only one study was identified from central America (Mexico), encompassing 165 tested patients, and one study from Oceania (New Zealand) of 500 tested patients.

The unweighted mean age across all studies where age was recorded ranged from 53.0 to 71.4 years, with $25.0-75.1 \%$ male and $40.4-100 \%$ of patients having adenocarcinoma. Table 1 provides a summary of all of the studies included in this analysis [25-98].

\subsection{All EGFR Mutation Analysis}

The final model for the All EGFR mutation analysis included one covariate term for percentage of male patients (at the $0.001 \%$ level). The percentage of adenocarcinomas was investigated in the model as an additive covariate but was not statistically significant, and thus was not included in the final model. Estimates for the prevalence of All EGFR mutations ranged from $11.9 \%$ (95\% confidence interval [CI] 6.7-20.5) for Global to 49.1\% (95\% CI 46.5-51.7) for Asia (Fig. 2). The model was a good fit for the data as evidenced by the minimal difference between observed values and predicted estimates (Electronic Supplementary Material [ESM]). An informal assessment of the effect of study percentage of male patients as a covariate found that as the percentage of male patients increased, the percentage of All EGFR mutations decreased for all continents (Table 2).

\subsection{Exon 19 Deletions}

There were no significant covariates. Estimates for the prevalence of the exon 19 deletion submutation, which were relative to the overall EGFR mutation population, ranged from $40.3 \%$ (95\% CI 28.1-53.9) for Oceania to $66.8 \%$ (95\% CI 51.7-79.0) for South America (Fig. 3). The CIs for the model estimates were not as precise as those for the All EGFR mutation model. This was because the study populations were smaller for this analysis, as only the number of patients with EGFR mutations was included (ESM).

\subsection{Exon 21 L858R Substitutions}

Similar to the exon 19 deletion analysis, there were no significant covariates for the exon 21 L858R substitution analysis, thus the base model was the final model. Estimates for the prevalence of the exon 21 L858R substitutions, which were relative to the overall EGFR mutation population, ranged from $27.7 \%$ (95\% CI 17.3-41.2) for South America to $41.1 \%$ (95\% CI 39.6-42.7) for Asia (Fig. 4). The CIs for the model estimates were not as precise as those for the All EGFR mutation model because the study populations were smaller for this analysis as only the number of patients with $E G F R$ mutations was included (ESM). 
Table 1 Characteristics of included studies

\begin{tabular}{|c|c|c|c|c|c|c|c|c|c|c|}
\hline $\begin{array}{l}\text { Study } \\
\text { number }\end{array}$ & Region & $\begin{array}{l}\text { No. of } \\
\text { patients } \\
\text { tested for } \\
\text { EGFR }\end{array}$ & $\begin{array}{l}\text { Mean age, } \\
\text { years }\end{array}$ & Male, $\%$ & $\begin{array}{l}\text { Adenocarci- } \\
\text { noma, } \%\end{array}$ & $\begin{array}{l}\text { All EGFR } \\
\text { mutation, \% }\end{array}$ & $\begin{array}{l}\text { EGFR } \\
\text { exon } 19 \\
\text { dele- } \\
\text { tions, } \%^{\text {a }}\end{array}$ & $\begin{array}{l}\text { Exon } 21 \\
\text { L858R substi- } \\
\text { tutions, } \%^{\mathrm{a}}\end{array}$ & $\begin{array}{l}\text { Other } \\
\text { submuta- } \\
\text { tions, } \%^{\mathrm{a}}\end{array}$ & References \\
\hline 1 & Europe & 282 & 64.0 & 45.7 & 100.0 & b & 45.0 & 28.0 & 27.0 & {$[25]$} \\
\hline 2 & Europe & 2052 & N/A & N/A & N/A & 10.6 & 41.3 & 32.1 & 26.6 & [26] \\
\hline 3 & Europe & 181 & 71.4 & 38.1 & 89.0 & b & 57.1 & 22.6 & 20.3 & [27] \\
\hline 4 & Europe & $360^{c}$ & 62.0 & 47.5 & 97.5 & 15.3 & 42.5 & 40.0 & 17.5 & [28] \\
\hline 5 & Europe & 778 & N/A & 54.1 & 79.7 & 9.1 & 54.9 & 29.6 & 15.5 & [29] \\
\hline 6 & Europe & 462 & 66.0 & 49.4 & 68.2 & 12.3 & 57.9 & 22.8 & 19.3 & [30] \\
\hline 7 & Europe & 4196 & 66.0 & 62.1 & 69.4 & 10.3 & 48.3 & 35.3 & 16.5 & {$[31]$} \\
\hline 8 & Europe & 1201 & N/A & 61.2 & 84.1 & 9.8 & 61.0 & 22.9 & 16.1 & [32] \\
\hline 9 & Europe & 753 & 65.0 & 62.0 & 80.0 & 16.1 & 47.3 & 24.8 & 27.9 & [33] \\
\hline 10 & Europe & 3269 & 68.4 & 52.6 & 46.6 & 9.3 & 38.9 & 30.4 & 30.4 & [34] \\
\hline 11 & Europe & 1427 & 61.0 & 75.1 & 40.4 & 8.9 & 52.0 & 42.5 & 5.5 & [35] \\
\hline 12 & Europe & 1785 & 64.0 & 60.7 & 78.0 & 13.8 & 43.3 & 28.3 & 36.4 & [36] \\
\hline 13 & Asia & 484 & N/A & 57.6 & 88.4 & 37.6 & 56.6 & 33.5 & 9.9 & [37] \\
\hline 14 & Asia & 177 & 60.0 & 48.0 & 100.0 & $\mathrm{~b}$ & 53.1 & 40.1 & 13.6 & [38] \\
\hline 15 & Asia & 310 & 57.0 & 52.3 & 100.0 & 42.9 & 46.6 & 45.1 & 8.3 & [39] \\
\hline 16 & Asia & 627 & 58.0 & 61.1 & 87.7 & 38.8 & 53.5 & 40.3 & 6.2 & [40] \\
\hline 17 & Asia & 441 & 60.3 & 62.6 & 70.4 & 37.6 & 56.6 & 28.9 & 14.5 & [41] \\
\hline 18 & Asia & $1230^{\mathrm{d}}$ & N/A & N/A & 100.0 & 38.5 & 43.6 & 50.5 & 5.9 & [42] \\
\hline 19 & Asia & 74 & 59.0 & 25.0 & 97.0 & b & 50.0 & 46.0 & 4.0 & [43] \\
\hline 20 & Asia & 437 & 57.0 & 36.9 & N/A & 59.7 & 53.6 & 42.5 & 8.0 & [44] \\
\hline 21 & Asia & 134 & 57.0 & 57.7 & 75.7 & 50.7 & 60.3 & 29.4 & 10.3 & [45] \\
\hline 22 & Asia & 159 & 63.0 & 39.6 & 100.0 & b & 54.1 & 42.1 & 3.8 & [46] \\
\hline 23 & Asia & 1672 & N/A & 57.6 & N/A & 27.8 & 58.9 & 39.8 & 1.3 & [47] \\
\hline 24 & Asia & 69 & 61.0 & 60.9 & 100.0 & $\mathrm{~b}$ & 52.2 & 43.5 & 4.3 & [48] \\
\hline 25 & Asia & 741 & 57.4 & 53.0 & 100.0 & 50.2 & 48.9 & 45.4 & 5.6 & [49] \\
\hline 26 & Asia & 145 & 64.0 & 57.0 & 86.0 & 44.1 & 46.9 & 37.5 & 15.6 & [50] \\
\hline 27 & Asia & 1450 & 60.0 & 56.6 & 94.9 & 51.4 & 43.0 & 40.6 & 16.4 & [51] \\
\hline 28 & Asia & 879 & 63.0 & 50.8 & 78.6 & b & 48.0 & 48.7 & 3.3 & [52] \\
\hline 29 & Asia & 183 & N/A & 43.5 & 100.0 & 65.0 & 51.3 & 37.0 & 11.8 & [53] \\
\hline 30 & Asia & 178 & 68.0 & 49.4 & 100.0 & 53.4 & 35.8 & 51.6 & 12.6 & [54] \\
\hline 31 & Asia & 228 & 59.3 & 43.4 & 60.5 & $\mathrm{~b}$ & 53.1 & 38.2 & 8.8 & [55] \\
\hline 32 & Asia & 169 & 53.2 & 52.1 & 100.0 & 49.1 & 50.6 & 41.0 & 8.4 & [56] \\
\hline 33 & Asia & 552 & N/A & N/A & N/A & 64.5 & 40.2 & 42.7 & 17.1 & [57] \\
\hline 34 & Asia & 148 & 65.2 & 51.0 & 86.8 & $\mathrm{~b}$ & 49.5 & 41.8 & 8.8 & [58] \\
\hline 35 & Asia & $598^{\mathrm{e}}$ & 62.0 & 56.5 & 81.3 & 49.0 & 57.1 & 28.6 & 14.3 & [59] \\
\hline 36 & Asia & 169 & 56.0 & 68.6 & 100.0 & 37.9 & 57.8 & 35.9 & 6.3 & [60] \\
\hline 37 & Asia & 496 & 62.0 & 45.8 & 100.0 & 58.7 & 40.2 & 38.8 & 21.0 & [61] \\
\hline 38 & Asia & 134 & 56.0 & 73.1 & 80.6 & b & 60.3 & 29.4 & 10.3 & [62] \\
\hline 39 & Asia & 109 & N/A & 46.8 & 100.0 & 56.9 & 50.0 & 37.1 & 12.9 & [63] \\
\hline 40 & Asia & 1632 & N/A & N/A & 100.0 & 51.5 & 42.1 & 42.4 & 15.5 & [64] \\
\hline 41 & Asia & 145 & 57.5 & 37.0 & 100.0 & b & 44.1 & 48.3 & 7.6 & [65] \\
\hline 42 & Asia & 16,840 & N/A & N/A & 100.0 & 35.0 & 44.6 & 44.7 & 10.6 & [66] \\
\hline 43 & Asia & 266 & 57.0 & 53.4 & 91.0 & 45.5 & 52.9 & 41.3 & 5.8 & [67] \\
\hline 44 & Asia & 69 & 56.0 & 55.1 & 88.4 & $\mathrm{~b}$ & 52.9 & 35.3 & 11.8 & [68] \\
\hline 45 & Asia & 575 & 59.6 & 62.7 & 70.5 & 36.3 & 56.5 & 29.7 & 13.9 & [69] \\
\hline 46 & Asia & 217 & 59.0 & 44.7 & 80.2 & 63.1 & 50.4 & 40.9 & 8.8 & [70] \\
\hline 47 & Asia & 949 & N/A & 58.7 & 100.0 & 51.4 & 44.5 & 45.9 & 9.6 & [71] \\
\hline
\end{tabular}


Table 1 (Continued)

\begin{tabular}{|c|c|c|c|c|c|c|c|c|c|c|}
\hline $\begin{array}{l}\text { Study } \\
\text { number }\end{array}$ & Region & $\begin{array}{l}\text { No. of } \\
\text { patients } \\
\text { tested for } \\
\text { EGFR }\end{array}$ & $\begin{array}{l}\text { Mean age, } \\
\text { years }\end{array}$ & Male, $\%$ & $\begin{array}{l}\text { Adenocarci- } \\
\text { noma, } \%\end{array}$ & $\begin{array}{l}\text { All } E G F R \\
\text { mutation, \% }\end{array}$ & $\begin{array}{l}\text { EGFR } \\
\text { exon } 19 \\
\text { dele- } \\
\text { tions, } \% \text { a }\end{array}$ & $\begin{array}{l}\text { Exon } 21 \\
\text { L858R substi- } \\
\text { tutions, } \%^{\mathrm{a}}\end{array}$ & $\begin{array}{l}\text { Other } \\
\text { submuta- } \\
\text { tions, \% }\end{array}$ & References \\
\hline$\overline{48}$ & Asia & 259 & 68.0 & 64.5 & 70.0 & 28.2 & 56.2 & 31.5 & 12.3 & [72] \\
\hline 49 & Asia & 812 & 59.0 & 51.0 & 100.0 & 39.5 & 59.5 & 37.7 & 6.5 & [73] \\
\hline 50 & Asia & 246 & 68.0 & 58.0 & 100.0 & 39.8 & 42.9 & 53.1 & 5.1 & [74] \\
\hline 51 & Asia & 207 & 60.8 & 37.7 & 97.1 & b & 52.7 & 42.0 & 5.3 & [75] \\
\hline 52 & Asia & 1195 & N/A & 56.4 & 90.8 & 46.4 & 42.3 & 40.0 & 17.7 & [76] \\
\hline 53 & Asia & 229 & 61.0 & 55.5 & 48.9 & 52.4 & 50.1 & 41.7 & 8.3 & [77] \\
\hline 54 & Asia & 220 & 59.0 & 55.9 & 80.0 & 51.8 & 56.1 & 30.7 & 20.2 & [78] \\
\hline 55 & Asia & 206 & 55.8 & 47.6 & 100.0 & 51.5 & 44.3 & 40.6 & 15.1 & [79] \\
\hline 56 & Asia & 90 & 66.7 & 35.8 & 91.5 & 61.1 & 36.4 & 41.8 & 21.8 & [80] \\
\hline 57 & Asia & 265 & N/A & 45.3 & 100.0 & 55.8 & 45.9 & 47.3 & 6.8 & [81] \\
\hline 58 & Asia & 170 & 57.1 & 54.7 & 85.3 & 58.2 & 40.4 & 47.5 & 12.1 & [82] \\
\hline 59 & Asia & 352 & 59.0 & 49.1 & 77.6 & 64.8 & 53.5 & 44.7 & 1.8 & [83] \\
\hline 60 & Asia & 140 & 57.5 & 64.3 & 59.3 & 72.9 & 32.4 & 35.3 & 32.4 & [84] \\
\hline 61 & Asia & 100 & 53.0 & 57.0 & 90.0 & 51.0 & 51.0 & 35.3 & 13.7 & [85] \\
\hline 62 & Asia & 246 & 67.0 & 63.0 & 100.0 & 41.0 & 45.0 & 48.0 & 7.0 & [86] \\
\hline 63 & Asia & 171 & 61.0 & 53.2 & N/A & $\mathrm{b}$ & 54.1 & 44.4 & 1.5 & [87] \\
\hline 64 & N. America & 860 & N/A & 41.2 & 100.0 & 27.0 & 48.3 & 30.2 & 21.6 & [88] \\
\hline 65 & N. America & 289 & 62.4 & 40.0 & 100.0 & 18.7 & 33.3 & 27.8 & 38.9 & [89] \\
\hline 66 & N. America & 838 & 61.0 & 40.6 & 100.0 & 22.7 & 44.7 & 26.3 & 28.9 & [90] \\
\hline 67 & N. America & 336 & 61.0 & 41.0 & 87.0 & 16.7 & 41.1 & 35.7 & 30.4 & [91] \\
\hline 68 & N. America & 1009 & 66.0 & 41.1 & 89.1 & 19.0 & 41.1 & 31.3 & 27.6 & [92] \\
\hline 69 & $\begin{array}{l}\text { Central } \\
\text { America }\end{array}$ & 165 & N/A & 40.3 & 100.0 & 41.8 & 46.3 & 33.3 & 20.4 & [93] \\
\hline 70 & Oceania & 500 & 70.0 & 49.8 & 61.4 & 21.8 & 40.4 & 33.0 & 26.6 & [94] \\
\hline 71 & S. America & 72 & 62.0 & 26.4 & 100.0 & $\mathrm{~b}$ & 66.7 & 27.8 & 5.6 & [95] \\
\hline 72 & Global & 129 & 61.0 & 42.0 & 100.0 & b & 40.0 & 42.0 & 18.0 & [96] \\
\hline 73 & Global & 121 & 61.5 & 50.4 & 71.1 & $\mathrm{~b}$ & 56.2 & 27.3 & 16.5 & [97] \\
\hline 74 & Global & $1048^{\mathrm{f}}$ & 61.2 & 59.1 & 93.0 & 10.4 & 50.5 & 35.8 & 13.8 & [98] \\
\hline
\end{tabular}

EGFR epidermal growth factor receptor, $N$ north, $N / A$ not available, $S$ south

${ }^{\text {a }}$ Relative to the overall $E G F R$ mutation population

${ }^{\mathrm{b}}$ Study was excluded from the All EGFR mutation analysis

${ }^{\mathrm{c}} n=40$ for submutation analyses

${ }^{\mathrm{d}} n=872$ for submutation analyses

${ }^{\mathrm{e}} n=99$ for submutation analyses

${ }^{\mathrm{f}} n=109$ for submutation analyses

\section{Discussion and Conclusions}

This systematic review and meta-analysis showed that the prevalence of $E G F R$ mutations in patients with advanced NSCLC differed with geographic region. The highest prevalence for All EGFR mutations was observed in Asian patients (49.1\%) compared with other continents (11.9-33.0\%). These results are similar to another systematic review that found the overall rate of EGFR mutations was lowest for Europe (14.1\%) and highest for Asia (38.4\%), with a combined North and South America region in the middle (24.4\%) [99]. However, this study did not restrict the population to patients with advanced NSCLC, did not distinguish between specific EGFR submutations, comprising only $73 \%$ of patients with adenocarcinoma, and characterized regions more broadly. Other systematic reviews have also been published; however, these studies did not analyze EGFR mutation incidence according to the same criteria as in the present study [100-104]. Our study was unique in that it also examined the prevalence of the most prominent TKI-sensitizing submutations. Although there were regional differences in the distribution of submutations 
Fig. 2 Final model estimates for the All EGFR mutation analysis with percent male covariate. Blue symbols indicate observed data. $C I$ confidence interval, $E G F R$ epidermal growth factor receptor

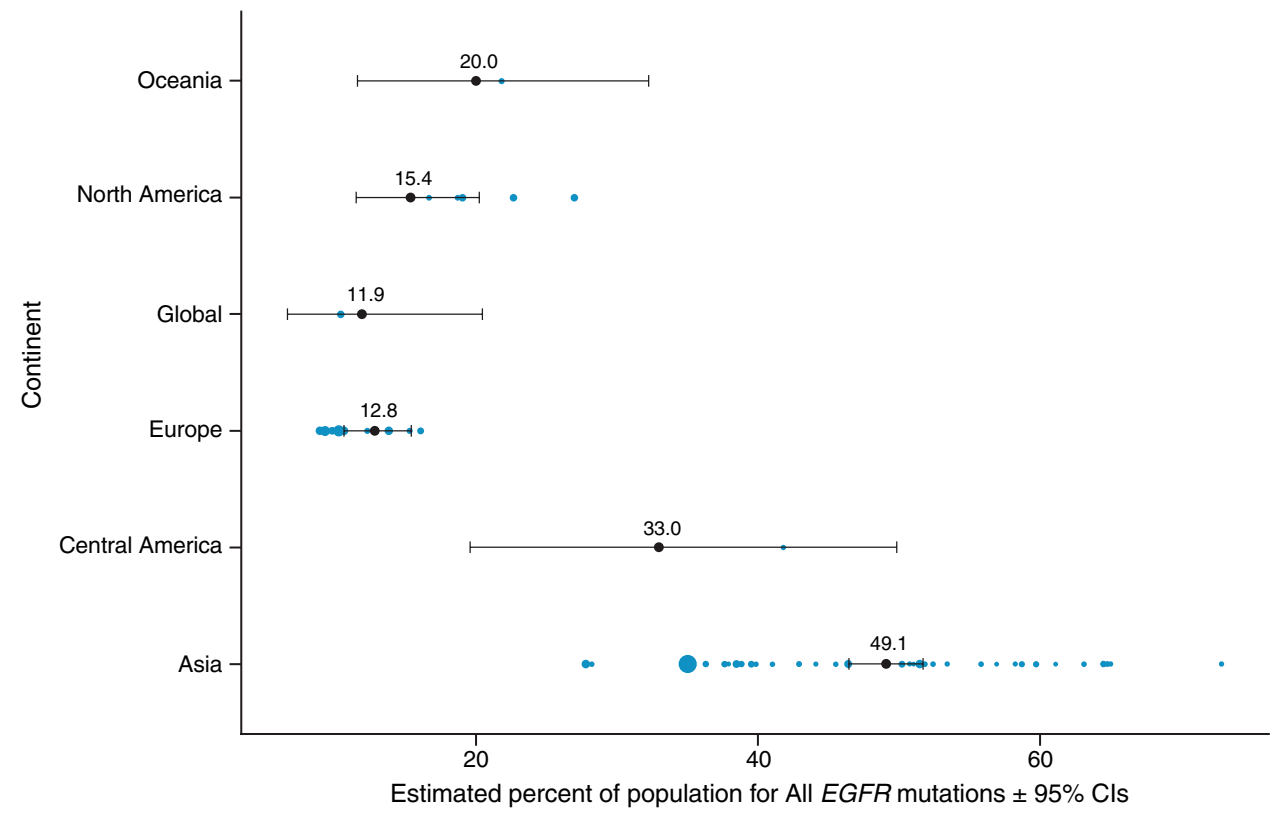

Table 2 Effect of study percentage of male patients on All EGFR mutation estimates

\begin{tabular}{lllc}
\hline Continent term & \multicolumn{3}{l}{ All EGFR mutation rate (\%) } \\
\cline { 2 - 4 } & $30 \%$ Male & $50 \%$ Male & $70 \%$ Male \\
\hline Europe (intercept) & 22.4 & 14.0 & 8.4 \\
Asia & 65.4 & 51.6 & 37.6 \\
Central America & 26.2 & 16.7 & 10.2 \\
North America & 49.1 & 35.2 & 23.5 \\
Oceania & 32.9 & 21.7 & 13.5 \\
Global & 21.0 & 13.0 & 7.8 \\
\hline
\end{tabular}

EGFR epidermal growth factor receptor

(exon 19 deletions and exon 21 L858R substitutions), these differences were less pronounced than for the overall EGFR mutation analysis.

For the overall EGFR mutation analysis, the percentage of male patients in the study population was identified as a significant covariate. Percent adenocarcinoma and age were not determined to be significant covariates. As the percentage of male patients increased, the percentage of overall $E G F R$ mutations decreased. It is well recognized that not only do female patients with NSCLC have a decreased risk of progression and death, they also have a greater incidence of EGFR mutations and respond better to EGFR TKI therapy than male patients [51, 99, 101-103, 105-107]. Importantly, our study did not find any covariates, including percentage of male patients in the study population, that were meaningful in terms of individual submutations. It is concluded, therefore, that testing for mutations is crucial regardless of sex and other patient characteristics. However, our study did not investigate the influence of other covariates, such as smoking status, that have been shown to be associated with an increased incidence of EGFR mutations [108]. The studies included in our analysis used very different forms of categorization for smoking behaviors (e.g., some studies used "yes/no" only, while others used "heavy/light/former/ never"), which made it difficult to standardize; furthermore, we believe an influence of smoking status on submutations was unlikely.

Although a strength of this analysis was that it investigated EGFR mutation and submutation status in a large meta-analysis on a worldwide basis, the number of patients in certain geographic regions was limited. The majority of studies came from Europe and Asia; there was only one study from South America included in the submutation analyses and this study was not included in the overall EGFR mutation analysis. This low number of studies from central and South America may be because EGFR mutation testing is low in Latin American countries, potentially as a result of lack of access [109]. A recent analysis of 4389 patients has shown that molecular testing is requested in only $76 \%$ of lung-cancer cases in Latin America, compared with 97\%, $79 \%$, and $90 \%$ in the USA, Europe, and Japan, respectively [110]. Moreover, specific regions may have high diversity in $E G F R$ mutation prevalence, which was not captured in our analysis because data on race and ethnicity were scarce in many publications, thus geographical region was used. This has been seen in Asia, for example, where EGFR mutation frequency has been shown to range from $22 \%$ in those of Vietnamese ethnicity to $64 \%$ in those of Indian ethnicity [51]. Another potential limitation is that the patient populations in each of the studies included in the analysis may have been more likely to be selected for EGFR mutation testing 
Fig. 3 Final model estimates for the exon 19 deletion $E G F R$ submutation analysis ${ }^{\mathrm{a}}$. Blue symbols indicate observed data. ${ }^{a}$ Relative to the overall EGFR mutation population. $C I$ confidence interval, EGFR epidermal growth factor receptor
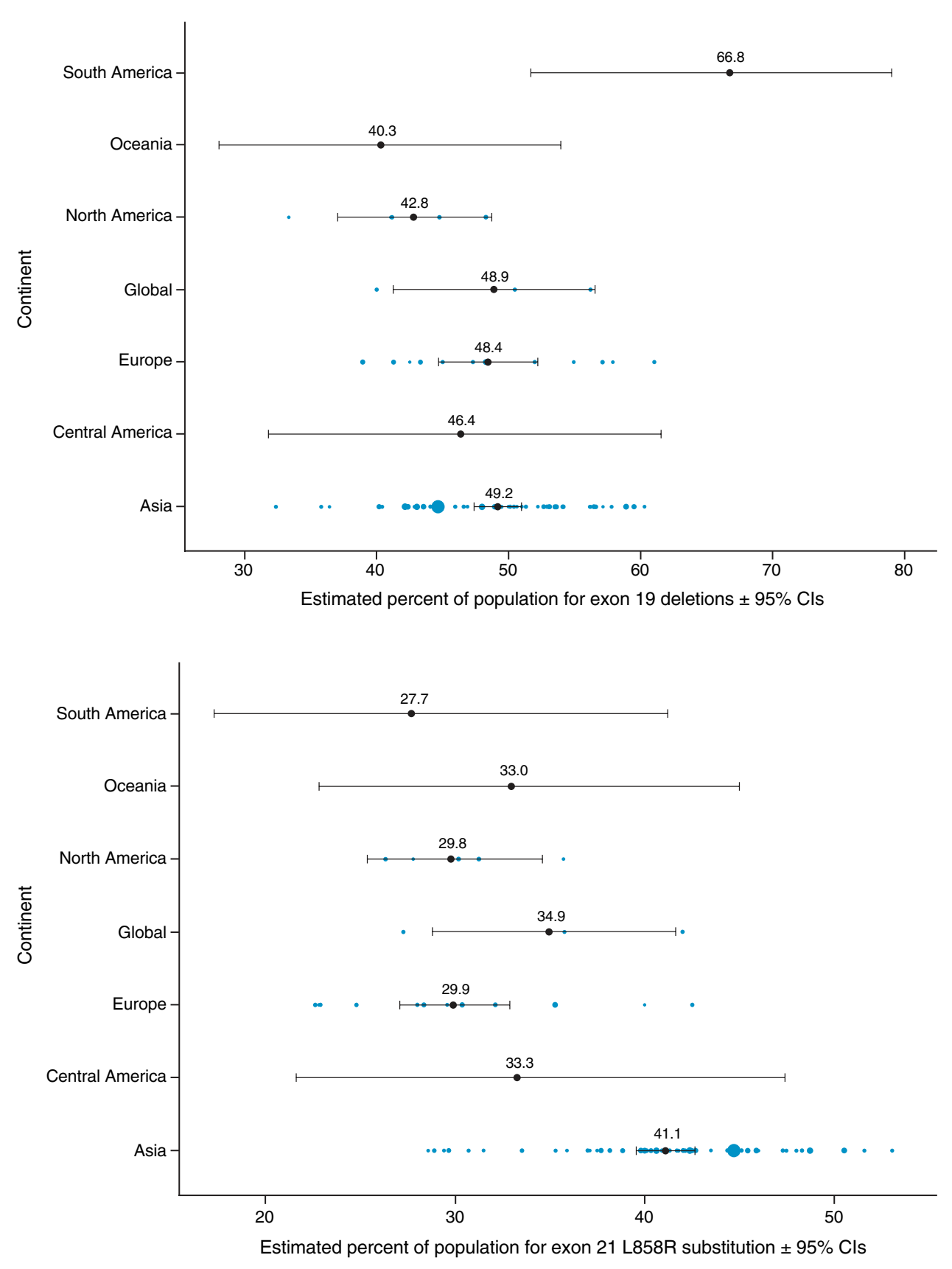

Fig. 4 Final model estimates for the exon 21 L858R substitution EGFR submutation analysis ${ }^{\mathrm{a}}$. Blue symbols indicate observed data. ${ }^{a}$ Relative to the overall $E G F R$ mutation population. $C I$ confidence interval, EGFR epidermal growth factor receptor based on demographic and/or clinical characteristics, availability of specimens for testing, or they may be from areas where testing is more common [111, 112]. Nevertheless, our model was a good fit for the data for the overall EGFR mutation analysis as evidenced by the minimal difference between observed values and predicted estimates, so that the different proportions of patients positive for EGFR mutations among the various regions should be upheld even if exact rates are indefinite. Linear mixed-effects logistic regression was utilized because it is an established meta-analysis methodology, which uses the totality of the data in a unified framework for more precise mean estimates and easier estimation of covariate effects. This approach allowed for continent and covariate effects for each EGFR mutation endpoint to be analyzed simultaneously.

Our analysis focused on exon 19 deletions and exon 21 L858R substitutions. We did not examine other submutations (e.g., exon 20) because of a lack of available data. Additionally, because the most common mutations are in-frame deletions of exon 19 and L858R substitutions in exon 21, we thought that these would be the most clinically relevant [8, 11]. Less common EGFR mutations and complex mutations represent a heterogeneous subgroup of patients, and differences in testing methods used for different studies may also 
introduce a bias, such as a false-negative result, when analyzing rarer mutations [12]. Although our analysis was based on NSCLC overall, generally most of the patients in the included studies had adenocarcinoma histology. Because of infrequent reporting of actionable mutations in other histologies, current guidelines focus mainly on testing patients with adenocarcinoma and advise that molecular testing is appropriate in NSCLC with nonadenocarcinoma histology when clinical features are atypical or there is an increased likelihood of a targetable mutation [12]. The prevalence of EGFR mutations and submutations may therefore differ between histological subtypes and data availability may be affected by differences in testing patterns and clinical features.

Understanding EGFR mutation prevalence in different geographic regions is important for physicians who need to make informed decisions for their patients that are based on sound medical evidence of benefit. This information is also critical so that policy and guidelines can be optimally developed to account for the EGFR genetic profile of local populations, which is not only important in resource-limited settings, but also around the globe where there is an increasing emphasis on personalized yet cost-effective practice of care [113-115]. This meta-analysis provided a robust and comprehensive overview of EGFR mutation and submutation prevalence, and identified an important covariate (percentage male) that influenced EGFR mutation status in patients with advanced NSCLC worldwide. These data show that despite differences among geographic regions, there is a considerable percentage of patients with either of the main types of actionable mutations (exon 19 deletions and exon 21 L858R substitutions) who could potentially benefit from targeted therapies. Thus, these data support the adoption of widespread routine testing in the advanced setting to improve therapeutic outcomes for these patients.

Supplementary Information The online version contains supplementary material available at https://doi.org/10.1007/s40291-021-00563-1.

Acknowledgements We thank Eckart Laack, Hemato-Oncology Hamburg, Hamburg, Germany, for his contribution in interpreting the data We also thank Meredith Rogers, MS, CMPP, from CMC AFFINITY, McCann Health Medical Communications (Hackensack, NJ, USA), for providing editorial support, which was funded by Pfizer Inc.

\section{Declarations}

Funding This research was sponsored by Pfizer Inc.

Conflicts of Interest/Competing Interests BM reports receiving honoraria from AstraZeneca, Boehringer Ingelheim, Bristol Myers Squibb, Eli Lilly, Merck, Novartis, and Pfizer. KK declares no conflicts of interest. MH reports receiving advisory fees/honoraria from BMS GmbH \& Co. KG, Boehringer Ingelheim, Chugai Pharma Germany GmbH, Pfizer Pharma GmbH, and Roche Pharma AG, and grants for scientific research from AstraZeneca. MB is a Pfizer employee and may hold Pfizer stock. DJN is a Pfizer employee and may hold Pfizer stock. JB is a Pfizer employee and may hold Pfizer stock. AK is a Pfizer employee and may hold Pfizer stock. MM was a Pfizer employee at the time of preparation of the publication and may hold Pfizer stock. He is currently an employee of AbbVie and owns stock in AbbVie. FC reports being a consultant and participating in advisory boards for AstraZeneca, Bristol Myers Squibb, Eli Lilly, MSD, Pfizer, Roche, and Takeda.

Ethics Approval Not applicable.

Consent to Participate Not applicable.

Consent for Publication Not applicable.

Availability of Data and Material Not applicable.

Code Availability Not applicable.

Authors' Contributions $\mathrm{BM}, \mathrm{KK}, \mathrm{MH}$, and $\mathrm{FC}$ were involved in interpreting the data. MB, DJN, JB, and MM designed the research, conducted the research, and analyzed and interpreted the data. AK conducted the research, and analyzed and interpreted the data. All authors contributed to the development of this manuscript, and read and approved the final version.

Open Access This article is licensed under a Creative Commons Attribution-NonCommercial 4.0 International License, which permits any non-commercial use, sharing, adaptation, distribution and reproduction in any medium or format, as long as you give appropriate credit to the original author(s) and the source, provide a link to the Creative Commons licence, and indicate if changes were made. The images or other third party material in this article are included in the article's Creative Commons licence, unless indicated otherwise in a credit line to the material. If material is not included in the article's Creative Commons licence and your intended use is not permitted by statutory regulation or exceeds the permitted use, you will need to obtain permission directly from the copyright holder. To view a copy of this licence, visit http://creativecommons.org/licenses/by-nc/4.0/.

\section{References}

1. Bray F, et al. Global cancer statistics 2018: GLOBOCAN estimates of incidence and mortality worldwide for 36 cancers in 185 countries. CA Cancer J Clin. 2018;68(6):394-424.

2. Cancer.Net. Lung cancer: non-small cell: statistics. 28 July 2020. https://www.cancer.net/cancer-types/lung-cancer-non-small-cell/ statistics. Accessed 26 Oct 2021.

3. Meza R, et al. Lung cancer incidence trends by gender, race and histology in the United States, 1973-2010. PLoS ONE. 2015;10(3): e0121323.

4. Duffy MJ, O'Byrne K. Tissue and blood biomarkers in lung cancer: a review. Adv Clin Chem. 2018;86:1-21.

5. American Cancer Society. Lung cancer early detection, diagnosis, and staging. American Cancer Society; 2021.

6. National Cancer Institute. Surveillance, Epidemiology, and End Results Program. Adenocarcinoma of the lung and bronchus recent trends in SEER age-adjusted incidence rates, 2000-2017. 2021.

7. Villalobos P, Wistuba II. Lung cancer biomarkers. Hematol Oncol Clin North Am. 2017;31(1):13-29.

8. Herbst RS. Review of epidermal growth factor receptor biology. Int J Radiat Oncol Biol Phys. 2004;59(2 Suppl.):21-6. 
9. Hirsch FR, et al. New and emerging targeted treatments in advanced non-small-cell lung cancer. Lancet. 2016;388(10048):1012-24.

10. Pavelic K, et al. Evidence for a role of EGF receptor in the progression of human lung carcinoma. Anticancer Res. 1993;13(4):1133-7.

11. Sharma SV, et al. Epidermal growth factor receptor mutations in lung cancer. Nat Rev Cancer. 2007;7(3):169-81.

12. Lindeman NI, et al. Updated molecular testing guideline for the selection of lung cancer patients for treatment with targeted tyrosine kinase inhibitors: guideline from the College of American Pathologists, the International Association for the Study of Lung Cancer, and the Association for Molecular Pathology. J Thorac Oncol. 2018;13(3):323-58.

13. Aggarwal C, et al. Strategies for the successful implementation of plasma-based NSCLC genotyping in clinical practice. Nat Rev Clin Oncol. 2021;18(1):56-62.

14. Schiller JH, et al. Comparison of four chemotherapy regimens for advanced non-small-cell lung cancer. N Engl J Med. 2002;346(2):92-8.

15. Ohe Y, et al. Randomized phase III study of cisplatin plus irinotecan versus carboplatin plus paclitaxel, cisplatin plus gemcitabine, and cisplatin plus vinorelbine for advanced non-small-cell lung cancer: Four-Arm Cooperative Study in Japan. Ann Oncol. 2007;18(2):317-23.

16. Kerr KM, et al. Second ESMO consensus conference on lung cancer: pathology and molecular biomarkers for non-small-cell lung cancer. Ann Oncol. 2014;25(9):1681-90.

17. Lindeman NI, et al. Molecular testing guideline for selection of lung cancer patients for EGFR and ALK tyrosine kinase inhibitors: guideline from the College of American Pathologists, International Association for the Study of Lung Cancer, and Association for Molecular Pathology. Arch Pathol Lab Med. 2013;137(6):828-60.

18. Howlader $\mathrm{N}$, et al. The effect of advances in lung-cancer treatment on population mortality. N Engl J Med. 2020;383(7):640-9.

19. John A, et al. Value of precision medicine in advanced non-small cell lung cancer: real-world outcomes associated with the use of companion diagnostics. Oncologist. 2020;25(11):e1743-52.

20. Moher D, et al. Preferred reporting items for systematic reviews and meta-analyses: the PRISMA statement. BMJ. 2009;339:b2535.

21. PDQ ${ }^{\circledR}$ Adult Treatment Editorial Board. PDQ non-small cell lung cancer treatment. Bethesda, MD: National Cancer Institute. Updated 12 July 2021. https://www.cancer.gov/types/lung/ hp/non-small-cell-lung-treatment-pdq. Accessed 17 Sep 2021.

22. R Core Team. R: a language and environment for statistical computing. R Foundation for Statistical Computing, Vienna, Austria. 2019. http://www.r-project.org/index.html. Accessed 26 Oct 2021.

23. Bates D, et al. Fitting linear mixed-effects models using lme4. J Stat Softw. 2015;67(1):1-48.

24. Wickham H. ggplot2: elegant graphics for data analysis. In: Gentleman R, Hornik K, Parmigiani G (eds.) 1st edn, New York: Springer; 2016. p. 260. https://doi.org/10.1007/ 978-0-387-98141-3.

25. Zhao J, et al. CT characteristics in pulmonary adenocarcinoma with epidermal growth factor receptor mutation. PLoS ONE. 2017;12(9): e0182741.

26. Kuijpers C, et al. Association of molecular status and metastatic organs at diagnosis in patients with stage IV non-squamous nonsmall cell lung cancer. Lung Cancer. 2018;121:76-81.

27. Arriola E, et al. Clinical management and outcome of patients with advanced NSCLC carrying EGFR mutations in Spain. BMC Cancer. 2018;18(1):106.
28. Salvador-Coloma C, et al. Early radiological response as predictor of overall survival in non-small cell lung cancer (NSCLC) patients with epidermal growth factor receptor mutations. J Thorac Dis. 2018;10(3):1386-93.

29. Smits AJ, et al. EGFR and KRAS mutations in lung carcinomas in the Dutch population: increased EGFR mutation frequency in malignant pleural effusion of lung adenocarcinoma. Cell Oncol (Dordr). 2012;35(3):189-96.

30. Weber B, et al. EGFR mutation frequency and effectiveness of erlotinib: a prospective observational study in Danish patients with non-small cell lung cancer. Lung Cancer. 2014;83(2):224-30.

31. Schuette $\mathrm{W}$, et al. EGFR mutation status and first-line treatment in patients with stage III/IV non-small cell lung cancer in Germany: an observational study. Cancer Epidemiol Biomark Prev. 2015;24(8):1254-61.

32. Gahr S, et al. EGFR mutational status in a large series of Caucasian European NSCLC patients: data from daily practice. Br J Cancer. 2013;109(7):1821-8.

33. Locatelli-Sanchez M, et al. Routine EGFR molecular analysis in non-small-cell lung cancer patients is feasible: exons 18-21 sequencing results of 753 patients and subsequent clinical outcomes. Lung. 2013;191(5):491-9.

34. Evans M, et al. The clinicopathological and molecular associations of PD-L1 expression in non-small cell lung cancer: analysis of a series of 10,005 cases tested with the $22 \mathrm{C} 3$ assay. Pathol Oncol Res. 2020;26(1):79-89.

35. Bichev SN, et al. Epidermal growth factor receptor mutations in East European non-small cell lung cancer patients. Cell Oncol (Dordr). 2015;38(2):145-53.

36. Ramlau R, et al. Epidermal growth factor receptor mutationpositive non-small-cell lung cancer in the real-world setting in Central Europe: the INSIGHT study. J Thorac Oncol. 2015;10(9):1370-4.

37. Sun JM, et al. Prognostic and predictive value of KRAS mutations in advanced non-small cell lung cancer. PLoS ONE. 2013;8(5): e64816.

38. Zhao XM, et al. Prognostic and predictive value of serum carcinoembryonic antigen levels in advanced non-small cell lung cancer patients with epidermal growth factor receptor sensitive mutations and receiving tyrosine kinase inhibitors. Oncotarget. 2017;8(41):70865-73.

39. $\mathrm{Li} \mathrm{H}$, et al. Prognostic role of the systemic immune-inflammation index in brain metastases from lung adenocarcinoma with different EGFR mutations. Genes Immun. 2019;20(6):455-61.

40. He YY, et al. Prognostic significance of genotype and number of metastatic sites in advanced non-small-cell lung cancer. Clin Lung Cancer. 2014;15(6):441-7.

41. Sun JM, et al. Real world impact of epidermal growth factor receptor mutation status on treatment patterns in patients with non-small cell lung cancer. Lung Cancer. 2013;80(2):191-6.

42. Tseng YH, et al. Epidermal growth factor receptor (EGFR)tyrosine kinase inhibitor treatment and salvage chemotherapy in EGFR-mutated elderly pulmonary adenocarcinoma patients. Oncologist. 2015;20(7):758-66.

43. Yang JC, et al. First-line pemetrexed plus cisplatin followed by gefitinib maintenance therapy versus gefitinib monotherapy in East Asian patients with locally advanced or metastatic nonsquamous non-small cell lung cancer: a randomised, phase 3 trial. Eur J Cancer. 2014;50(13):2219-30.

44. Mok TS, et al. Gefitinib or carboplatin-paclitaxel in pulmonary adenocarcinoma. N Engl J Med. 2009;361(10):947-57.

45. Shi Y, et al. Icotinib versus gefitinib in previously treated advanced non-small-cell lung cancer (ICOGEN): a randomised, double-blind phase 3 non-inferiority trial. Lancet Oncol. 2013;14(10):953-61. 
46. Zhang P, et al. Impact of heavy smoking on the benefits from first-line EGFR-TKI therapy in patients with advanced lung adenocarcinoma. Medicine (Baltimore). 2018;97(9): e0006.

47. Wang BX, et al. Impacts of EGFR mutation and EGFR-TKIs on incidence of brain metastases in advanced non-squamous NSCLC. Clin Neurol Neurosurg. 2017;160:96-100.

48. Jin Y, et al. Mechanisms of primary resistance to EGFR targeted therapy in advanced lung adenocarcinomas. Lung Cancer. 2018;124:110-6.

49. Shi Y, et al. Molecular epidemiology of EGFR mutations in Asian patients with advanced non-small-cell lung cancer of adenocarcinoma histology: mainland China subset analysis of the PIONEER study. PLoS ONE. 2015;10(11): e0143515.

50. Ku BM, et al. Molecular screening of small biopsy samples using next-generation sequencing in Korean patients with advanced non-small cell lung cancer: Korean Lung Cancer Consortium (KLCC-13-01). J Pathol Transl Med. 2018;52(3):148-56.

51. Shi Y, et al. A prospective, molecular epidemiology study of EGFR mutations in Asian patients with advanced non-small-cell lung cancer of adenocarcinoma histology (PIONEER). J Thorac Oncol. 2014;9(2):154-62.

52. $\mathrm{Hu} \mathrm{X}$, et al. A single-arm, multicenter, safety-monitoring, phase IV study of icotinib in treating advanced non-small cell lung cancer (NSCLC). Lung Cancer. 2014;86(2):207-12.

53. Lee DW, et al. Additional prognostic role of EGFR activating mutations in lung adenocarcinoma patients with brain metastasis: integrating with lung specific GPA score. Lung Cancer. 2014;86(3):363-8.

54. Togashi Y, et al. Association between vascular-poor area of primary tumors and epidermal growth factor receptor gene status in advanced lung adenocarcinoma. Med Oncol. 2012;29(5):3169-75.

55. Yang RF, et al. Bevacizumab and gefitinib enhanced whole-brain radiation therapy for brain metastases due to non-small-cell lung cancer. Braz J Med Biol Res. 2017;51(1): e6073.

56. Lu RL, et al. Biological characteristics and epidermal growth factor receptor tyrosine kinase inhibitors efficacy of EGFR mutation and its subtypes in lung adenocarcinoma. Pathol Oncol Res. 2014;20(2):445-51.

57. Zhang G, et al. Bisphosphonates enhance antitumor effect of EGFR-TKIs in patients with advanced EGFR mutant NSCLC and bone metastases. Sci Rep. 2017;7:42979.

58. Kawase $S$, et al. Change in serum KL-6 level from baseline is useful for predicting life-threatening EGFR-TKIs induced interstitial lung disease. Respir Res. 2011;12(1):97.

59. Jiang $\mathrm{T}$, et al. Characterization of liver metastasis and its effect on targeted therapy in EGFR-mutant NSCLC: a multicenter study. Clin Lung Cancer. 2017;18(6):631-9.e2.

60. Paliwal P, et al. Clinical profile and outcomes of patients with stage IV adenocarcinoma of lung: a tertiary cancer center experience. Indian J Cancer. 2017;54(1):197-202.

61. Chung KP, et al. Clinical significance of thyroid transcription factor-1 in advanced lung adenocarcinoma under epidermal growth factor receptor tyrosine kinase inhibitor treatment. Chest. 2012;141(2):420-8.

62. Wang S, et al. Clinical significance of pretreatment plasma biomarkers in advanced non-small cell lung cancer patients. Clin Chim Acta. 2014;430:63-70.

63. Li Y, et al. Clinical validation of a highly sensitive assay to detect EGFR mutations in plasma cell-free DNA from patients with advanced lung adenocarcinoma. PLoS ONE. 2017;12(8): e0183331.

64. Shen YC, et al. Comparing the effects of afatinib with gefitinib or erlotinib in patients with advanced-stage lung adenocarcinoma harboring non-classical epidermal growth factor receptor mutations. Lung Cancer. 2017;110:56-62.
65. Miao Y, et al. Comparison of clinical and radiological characteristics between anaplastic lymphoma kinase rearrangement and epidermal growth factor receptor mutation in treatment naive advanced lung adenocarcinoma. J Thorac Dis. 2017;9(10):3927-37.

66. Zhang B, et al. Complex epidermal growth factor receptor mutations and their responses to tyrosine kinase inhibitors in previously untreated advanced lung adenocarcinomas. Cancer. 2018;124(11):2399-406.

67. Fang S, et al. Correlation between EGFR mutation status and response to first-line platinum-based chemotherapy in patients with advanced non-small cell lung cancer. Onco Targets Ther. 2014;7:1185-93.

68. Pan $\mathrm{H}$, et al. Effects of icotinib on advanced non-small cell lung cancer with different EGFR phenotypes. Cell Biochem Biophys. 2014;70(1):553-8.

69. Choi YL, et al. EGFR mutation testing in patients with advanced non-small cell lung cancer: a comprehensive evaluation of realworld practice in an East Asian tertiary hospital. PLoS ONE. 2013;8(2): e56011.

70. Park JH, et al. EGFR mutations as a predictive marker of cytotoxic chemotherapy. Lung Cancer. 2012;77(2):433-7.

71. Pi C, et al. EGFR mutations in early-stage and advanced-stage lung adenocarcinoma: analysis based on large-scale data from China. Thorac Cancer. 2018;9(7):814-9.

72. Baek MY, et al. Epidermal growth factor receptor mutation and pattern of brain metastasis in patients with non-small cell lung cancer. Korean J Intern Med. 2018;33(1):168-75.

73. Liam CK, et al. Epidermal growth factor receptor mutations in lung adenocarcinoma in Malaysian patients. J Thorac Oncol. 2013;8(6):766-72.

74. Fujimoto D, et al. Features and prognostic impact of distant metastasis in patients with stage IV lung adenocarcinoma harboring EGFR mutations: importance of bone metastasis. Clin Exp Metastasis. 2014;31(5):543-51.

75. Park K, et al. First-line erlotinib therapy until and beyond response evaluation criteria in solid tumors progression in Asian patients with epidermal growth factor receptor mutation-positive non-small-cell lung cancer: the ASPIRATION Study. JAMA Oncol. 2016;2(3):305-12.

76. Cheng Y, et al. Real-world EGFR testing in patients with stage IIIB/IV non-small-cell lung cancer in North China: a multicenter, non-interventional study. Thorac Cancer. 2018;9(11):1461-9.

77. Dong X, et al. Response to first-line chemotherapy in patients with non-small-cell lung cancer according to epidermal growth factor receptor and K-RAS mutation status. Clin Lung Cancer. 2013;14(6):680-7.

78. Sahoo R, et al. Screening for EGFR mutations in lung cancer, a report from India. Lung Cancer. 2011;73(3):316-9.

79. Zhang L, et al. SNPs in the transforming growth factor-beta pathway as predictors of outcome in advanced lung adenocarcinoma with EGFR mutations treated with gefitinib. Ann Oncol. 2014;25(8):1584-90.

80. Yang $\mathrm{CH}$, et al. Specific EGFR mutations predict treatment outcome of stage IIIB/IV patients with chemotherapy-naive nonsmall-cell lung cancer receiving first-line gefitinib monotherapy. J Clin Oncol. 2008;26(16):2745-53.

81. Han X, et al. Suitability of surgical tumor tissues, biopsy, or cytology samples for epidermal growth factor receptor mutation testing in non-small cell lung carcinoma based on Chinese population. Transl Oncol. 2014;7(6):795-9.

82. Tang Y, et al. The association between PD-L1 and EGFR status and the prognostic value of PD-L1 in advanced non-small cell lung cancer patients treated with EGFR-TKIs. Oncotarget. 2015;6(16):14209-19. 
83. Zhao M, et al. The Bim deletion polymorphism clinical profile and its relation with tyrosine kinase inhibitor resistance in Chinese patients with non-small cell lung cancer. Cancer. 2014;120(15):2299-307.

84. Zhang M, et al. The clinical significance of detection of EGFR mutation in peripheral blood of patients with advanced non-small cell lung cancer. Acta Medica Mediterranea. 2019;35:333-8.

85. Li B, et al. The correlation between EGFR mutation status and the risk of brain metastasis in patients with lung adenocarcinoma. J Neurooncol. 2015;124(1):79-85.

86. Sato Y, et al. The prognostic value of serum CA 19-9 for patients with advanced lung adenocarcinoma. BMC Cancer. 2016;16(1):890.

87. Wang W, Song A, Zhang Y. Zoledronic acid as potential efficacy application combined with icotinib for non-small cell lung cancer with bone metastases. Transl Cancer Res. 2017;6(1):129-35.

88. Jordan EJ, et al. Prospective comprehensive molecular characterization of lung adenocarcinomas for efficient patient matching to approved and emerging therapies. Cancer Discov. 2017;7(6):596-609.

89. Vigneswaran J, et al. Comprehensive genetic testing identifies targetable genomic alterations in most patients with non-small cell lung cancer, specifically adenocarcinoma, single institute investigation. Oncotarget. 2016;7(14):18876-86.

90. Steuer CE, et al. Role of race in oncogenic driver prevalence and outcomes in lung adenocarcinoma: results from the Lung Cancer Mutation Consortium. Cancer. 2016;122(5):766-72.

91. Cardarella $S$, et al. The introduction of systematic genomic testing for patients with non-small-cell lung cancer. J Thorac Oncol. 2012;7(12):1767-74.

92. VanderLaan PA, et al. Tumor biomarker testing in non-small-cell lung cancer: a decade of change. Lung Cancer. 2018;116:90-5.

93. Campos-Parra AD, et al. Relevance of the novel IASLC/ATS/ ERS classification of lung adenocarcinoma in advanced disease. Eur Respir J. 2014;43(5):1439-47.

94. McKeage M, et al. EGFR mutation testing of non-squamous NSCLC: impact and uptake during implementation of testing guidelines in a population-based registry cohort from northern New Zealand. Target Oncol. 2017;12(5):663-75.

95. Ruiz-Patino A, et al. EGFR amplification and sensitizing mutations correlate with survival in lung adenocarcinoma patients treated with erlotinib (MutP-CLICaP). Target Oncol. 2018;13(5):621-9.

96. Yang JC-H, et al. Afatinib for patients with lung adenocarcinoma and epidermal growth factor receptor mutations (LUX-Lung 2): a phase 2 trial. Lancet Oncol. 2012;13(5):539-48.

97. Ramalingam SS, et al. Dacomitinib versus erlotinib in patients with EGFR-mutated advanced nonsmall-cell lung cancer (NSCLC): pooled subset analyses from two randomized trials. Ann Oncol. 2016;27(3):423-9.

98. Scagliotti GV, et al. Tivantinib in combination with erlotinib versus erlotinib alone for EGFR-mutant NSCLC: an exploratory analysis of the phase 3 MARQUEE Study. J Thorac Oncol. 2018;13(6):849-54.

99. Zhang YL, et al. The prevalence of EGFR mutation in patients with non-small cell lung cancer: a systematic review and metaanalysis. Oncotarget. 2016;7(48):78985-93.
100. Dearden S, et al. Mutation incidence and coincidence in non small-cell lung cancer: meta-analyses by ethnicity and histology (mutMap). Ann Oncol. 2013;24(9):2371-6.

101. Szumera-Ciećkiewicz A, et al. EGFR mutation testing on cytological and histological samples in non-small cell lung cancer: a Polish, single institution study and systematic review of European incidence. Int J Clin Exp Pathol. 2013;6(12):2800-12.

102. Midha A, Dearden S, McCormack R. EGFR mutation incidence in non-small-cell lung cancer of adenocarcinoma histology: a systematic review and global map by ethnicity (mutMapII). Am J Cancer Res. 2015;5(9):2892-911.

103. Wang $S$, Wang $Z$. EGFR mutations in patients with non-small cell lung cancer from mainland China and their relationships with clinicopathological features: a meta-analysis. Int J Clin Exp Med. 2014;7(8):1967-78.

104. Ren JH, et al. EGFR mutations in non-small-cell lung cancer among smokers and non-smokers: a meta-analysis. Environ Mol Mutagen. 2012;53(1):78-82.

105. Pinto JA, et al. Gender and outcomes in non-small cell lung cancer: an old prognostic variable comes back for targeted therapy and immunotherapy? ESMO Open. 2018;3(3): e000344.

106. Buonerba $\mathrm{C}$, et al. Predictors of outcomes in patients with EGFRmutated non-small cell lung cancer receiving EGFR tyrosine kinase inhibitors: a systematic review and meta-analysis. Cancers (Basel). 2019;11(9):1259.

107. Shigematsu $\mathrm{H}$, et al. Clinical and biological features associated with epidermal growth factor receptor gene mutations in lung cancers. J Natl Cancer Inst. 2005;97(5):339-46.

108. Matsumura Y, et al. Epidermal growth factor receptor mutation status is strongly associated with smoking status in patients undergoing surgical resection for lung adenocarcinoma. Interact Cardiovasc Thorac Surg. 2017;25(5):690-5.

109. Raez LE, et al. Lung cancer disparities in Hispanics: molecular diagnosis and use of immunotherapy. JCO Glob Oncol. 2020;6:784-8.

110. Medimix International. NSCLC treatment paradigm: where do we stand? 2018. https://medimix.net/news/nsclc-biomarker-testi ng/. Accessed 30 Dec 2020.

111. Salto-Tellez M, et al. Clinical and testing protocols for the analysis of epidermal growth factor receptor mutations in East Asian patients with non-small cell lung cancer: a combined clinical-molecular pathological approach. J Thorac Oncol. 2011;6(10):1663-9.

112. Ellis PM, et al. Challenges to implementation of an epidermal growth factor receptor testing strategy for non-small-cell lung cancer in a publicly funded health care system. J Thorac Oncol. 2013;8(9):1136-41.

113. Greenberg D, et al. When is cancer care cost-effective? A systematic overview of cost-utility analyses in oncology. J Natl Cancer Inst. 2010;102(2):82-8.

114. Luengo-Fernandez R, et al. Economic burden of cancer across the European Union: a population-based cost analysis. Lancet Oncol. 2013;14(12):1165-74.

115. Faulkner E, et al. Challenges in the development and reimbursement of personalized medicine-payer and manufacturer perspectives and implications for health economics and outcomes research: a report of the ISPOR personalized medicine special interest group. Value Health. 2012;15(8):1162-71. 